\title{
Young male with long-term impaired ejection fraction - endocardial fibroelastosis: The importance of cardiac magnetic resonance
}

\author{
Varón joven con fracción de eyección deteriorada a largo plazo - fibroelastosis \\ endocárdica: la importancia de la resonancia magnética cardíaca \\ Alberto Alperi ${ }^{*}$, María Martín ${ }^{1}$, María Vigil-Escalera ${ }^{1}$, Iria Silva ${ }^{1}$, Helena Cigarrán ${ }^{2}$ and César Morís ${ }^{1}$ \\ ${ }^{1}$ Área del Corazón; ${ }^{2}$ Servicio de Radiodiagnóstico. Hospital Universitario Central de Asturias, Oviedo, Asturias, Spain
}

A 32-year-old male was referred to the cardiology outpatient clinic of our institution for follow-up of dilated cardiomyopathy. At the age of 3 months, he had presented significant dyspnea and an enlarged cardiac silhouette had been discovered at the chest X-ray. Echocardiography had showed the left atrium (LA) and left ventricle (LV) dilation with severely depressed LV ejection fraction (LVEF). A diagnosis of dilated cardiomyopathy was made at that time. He had been treated transitorily with loop diuretics and permanently with angiotensin-converting enzyme inhibitors and beta-blockers. He was stabilized and evolved in New York Heart Association functional Class II/IV reaching the adulthood.

His last transthoracic echocardiography showed markedly LA and LV dilation, moderately reduced (43\%) LVEF and trabeculated areas at the LV apical segments. Coronary artery disease was ruled out by a normal coronary angiography.

With the suspicion of non-compaction cardiomyopathy, a cardiac magnetic resonance (CMR) was requested. The cine steady-state free precession images demonstrated enlarge left cavities with moderately depressed LVEF, normal interventricular wall thickness, and right and left apical ventricular hypertrabeculation, although not fulfilling non-compaction criteria (Fig. 1).
At late gadolinium images, a diffused subendocardial late gadolinium hyperenhancement involving the basal and midsegments of the LV in a circumferential pattern was present (Fig. 2). At that time, etiological diagnosis of endocardial fibroelastosis (EFE) was performed.

EFE is a rare condition, whose primary form manifests most frequently during the $1^{\text {st }}$ month of life. It consists of a thickening of the endocardium by collagen and elastic fibers ${ }^{1}$. Its secondary form is mostly related to hypereosinophilia and lymphoproliferative disorders ${ }^{2}$. Primary EFE is mostly manifested with dilation and systolic impairment of the LV. However, there are primary EFE cases with features of other conditions such as restrictive cardiomyopathy ${ }^{3}$. A great number of cases have poor prognosis and require heart transplantation during childhood, some of them misdiagnosed mostly as dilated cardiomyopathy ${ }^{4}$.

There are not unified diagnostic criteria for this disease, what rends the diagnosis difficult during the adult age. A high grade of suspicion, comprehensive clinical history, and histological evidence of fibrosis either by biopsy or at the CMR are mandatory.

In our particular case, clinical history with onset at 3 months of age and diffused EFE evidenced at CMR enabled this diagnosis.

\section{Correspondence:}

*Alberto Alperi

Área del Corazón

Hospital Universitario Central de Asturias

Avda. de Roma, s/n

Date of reception: 14-05-2018

Date of acceptance: 10-10-2018

E-mail: alberto.alperi.garcia @ hotmail.com

DOI: 10.24875/ACM.M19000020
Available online: 08-04-2019 Arch Cardiol Mex. 2019;89(2):181-182 www.archivoscardiologia.com 1405-9940 @ 2018 Instituto Nacional de Cardiología Ignacio Chávez. Published by Permanyer México. This is an open access article under the CC BY-NC-ND license (http://creativecommons.org/licenses/by-nc-nd/4.0/). 


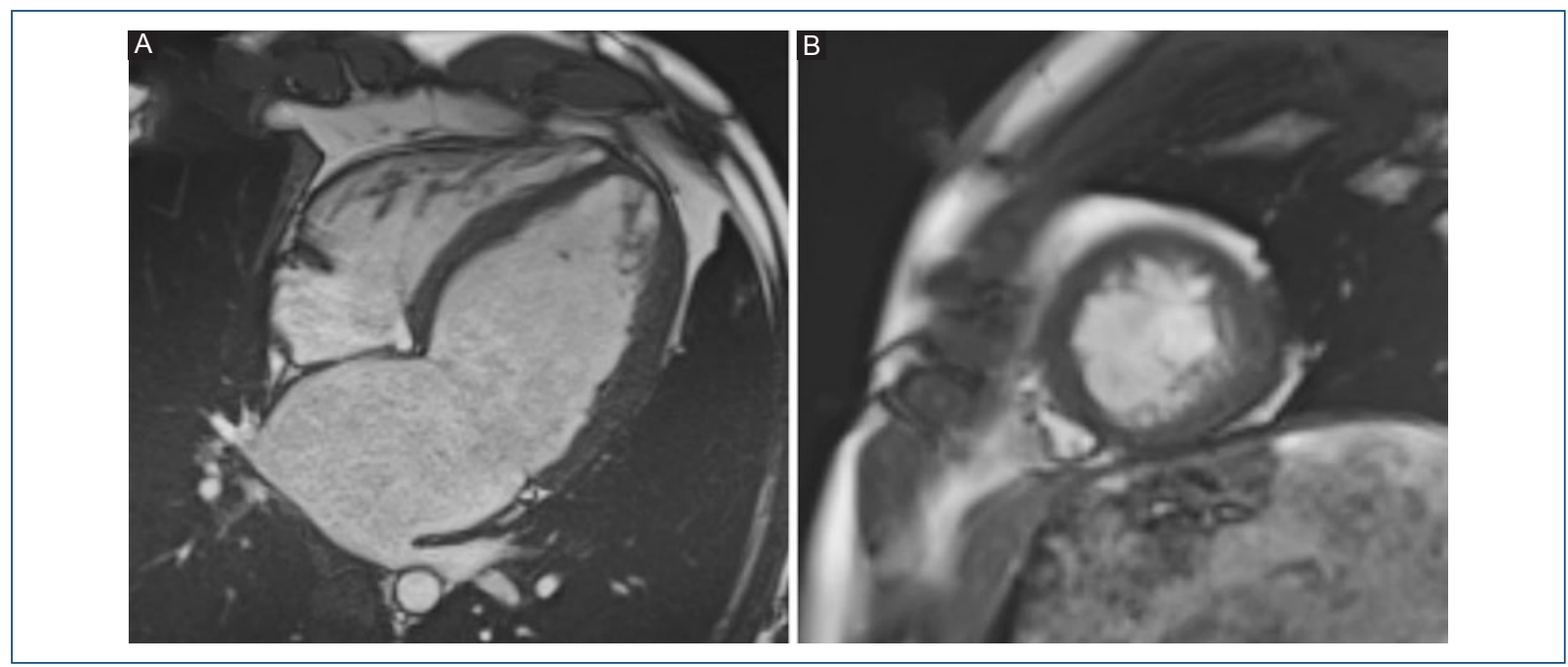

Figure 1. Cardiac magnetic resonance: cine steady-state free precession. Left atrium and left ventricle (LV) dilation with RV and LV trabeculation. (A) Four chamber view. (B) Midventricular short-axis view.

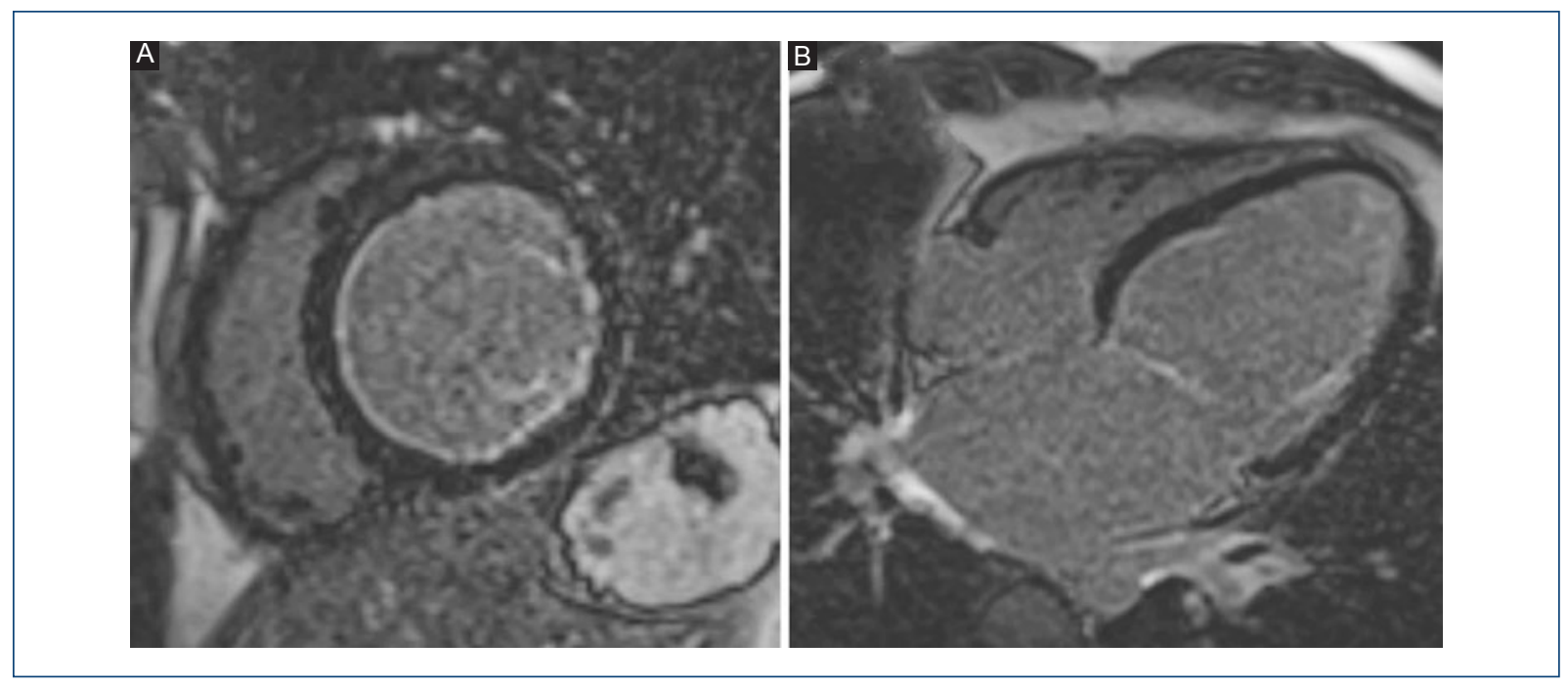

Figure 2. Cardiac magnetic resonance: late gadolinium enhancement sequence. Diffused subendocardial hyperenhancement. (A) Midventricular short-axis view. (B) Four chamber view.

\section{Conflicts of interest}

Authors do not have any conflicts of interest.

\section{Funding source}

No funding for this manuscript.

\section{Ethical disclosures}

Protection of human and animal subjects. The authors declare that no experiments were performed on humans or animals for this study.
Confidentiality of data. The authors declare that they have followed the protocols of their work center on the publication of patient data.

Right to privacy and informed consent. The authors declare that no patient data appear in this article.

\section{References}

1. Panke W, Rottino A. Endocardial fibroelastosis occurring in the adult. Am Heart J. 1955; 49:89-95.

2. Raman SV., Mehta R, Walker J, Pennell DJ. Cardiovascular magnetic resonance in endocardial fibroelastosis. J Cardiovasc Magn Reson. 2005;7(2):391-3.

3. Maredia N, English K, Greenwood J. Assessment of endocardial fibroelastosis by cardiac MRI. Can J Cardiol. 2008;24(5): e33 (only one page).

4. Seki A, Patel S, Ashraf S, Perens G, Fishbein MC. Primary endocardial fibroelastosis: An underappreciated cause of cardiomyopathy in children. Cardiovasc Pathol. 2013;22(5):345-50. 